\section{Efficiency of electricity distribution companies}

Electricity distribution companies

\author{
Diego Rodrigues Boente
}

FUCAPE Business School, Vitória, Brazil, and

Paulo Roberto B. Lustosa

Accounting and Actuarial Sciences, University of Brasilia, Brasilia, Brazil

\begin{abstract}
Purpose - After assessing papers on efficiency, most of the studies available are focused on the analysis of efficiency measures, without providing a deep discussion of the factors that determine efficiency. This study aims to evaluate the efficiency of Brazilian electricity distribution companies based on a structural model that enables the identification of a network of relationships among representative variables that contribute to efficiency.

Design/methodology/approach - Structural equation modeling was applied in a sample of 62 electricity distribution companies operating in Brazil, forming a balanced panel from 2010 to 2014. Then, the authors verified the model compliance according to the empirical evidence of the entities analyzed. This verification included a survey of the variables, which was supported by theoretical references related to the phenomenon studied. The data collected were statistically treated, and benchmarking models and multivariate techniques were used. Once the adjustments were made, the re-specified model was estimated using the maximum likelihood method.

Findings - The empirical model reached good adjustment rates. The analysis concluded that the constructs information system, structural system, management system and sociocultural system affect efficiency.

Originality/value - This study adds to several other papers, and this is one of its main contributions. Relationships among the constructs have been systematized according to literature in the form of a structural model, which will enable future researchers to have a reference frame of relevant studies and a research foundation in this area of knowledge. A third contribution is the model tested in a sample of Brazilian electricity distribution companies, whose results can be compared to other utility sectors (e.g. telecommunications) or to other countries' electrical sectors, thus providing an empirical basis for the proposed hypotheses. Finally, this study also offers a contribution to the Brazilian Electrical Energy Agency (Aneel, in Portuguese), a regulatory agency, providing mechanisms to guide tariff adjustments, seeking a balance between costs and the need for investments allied to tariff affordability.
\end{abstract}

Keywords Efficiency, Electrical sector, Structural equation modeling

Paper type Research paper

(C) Diego Rodrigues Boente and Paulo Roberto B. Lustosa. Published in RAUSP Management Journal. Published by Emerald Publishing Limited. This article is published under the Creative Commons Attribution (CC BY 4.0) licence. Anyone may reproduce, distribute, translate and create derivative works of this article (for both commercial and non-commercial purposes), subject to full attribution to the original publication and authors. The full terms of this licence may be seen at http:// creativecommons.org/licences/by/4.0/legalcode

Author contributions: Diego Rodrigues Boente lead on data curation, software, validation, visualization and writing the original draft. Paulo Roberto B. Lustosa and Diego Rodrigues Boente contributed equally on conceptualization, formal analysis, investigation, methodology, resources and review and editing.

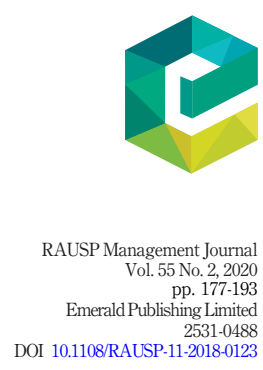


RAUSP

55,2

\section{Introduction}

The concept of efficiency is associated with an entity's ability to minimize its inputs or maximize its products, given certain market and technology conditions. Inefficiency occurs when the entity cannot reach the same level of efficiency as compared to a benchmark, as defined by a boundary of the entities that adopt "best practices" (benchmarking). This is the concept used in this study.

Laffont and Tirole (1986) emphasize the use of accounting data in regulation. According to the authors, when a regulated entity announces an expected cost for the service, it receives an incentive from the regulatory agency to reduce excess costs. Thus, the optimal contract includes a fixed price for the service, as the announced cost decreases.

It should be noted that entities can use cost information in their favor to unduly increase price. High costs may represent a particular situation of the entity and/or may occur due to inefficiency (Fillippini \& Wild, 2001). Because of information inconsistencies and inspection limitations, the regulatory agency does not know in advance the true level of the entity's efficiency and, therefore, uses estimates.

On the other hand, estimating efficiency from empirical data is a complex task considering the diversity of inputs and products. Shleifer (1985) points out that some aspects about efficiency estimation depend initially on the objectives pursued by the regulatory agency. A scheme that compares companies can reduce information inconsistencies between regulatory agencies and regulated companies (yardstick competition).

The most commonly used methods for this purpose include non-parametric methods, such as data envelopment analysis (DEA); and parametric ones, such as the stochastic frontier analysis (SFA).

Most of the studies available focus on efficiency measures, without providing a thorough discussion of the factors leading to efficiency variations. Focusing on efficiency estimation restrains the study to a particular sample or geographical area (Agrell, Farsi, Filippini, \& Koller, 2013; Cullmann, 2012).

In recent years, the intensive use of efficiency measures has raised serious concerns among regulatory agencies and entities, particularly as to the reliability of the estimates. Empirical evidence suggests that estimates are sensitive to two conditions: choice of the estimation model and heterogeneity among the entities compared (Greene, 2005).

Both conditions can have important effects on the financial and equity status of the entities and on the structure of the regulated sector, since tariffs are established, for example, based on the efficient operational costs estimated by the regulatory agency.

As the estimation of operating costs determines the electricity tariff, a change in the model can lead to an excessive burden on consumers if costs are overestimated, or an excessive burden on regulated entities if costs are underestimated. Thus, it is important to understand and discuss the variables that affect the efficiency of regulated entities as a factor of open interest by economic agents, regulatory agencies and consumers.

Considering all of the above, our study intends to answer the following research question:

RQ1. Which variables influence the efficiency of Brazilian electricity distribution companies?

The purpose of this research is to evaluate the efficiency of Brazilian electricity distribution based on the construction of a structural model that enables the identification of a structure of relationships between representative variables and efficiency.

This research area is very recent, and little discussed in Brazil and around the world, in the scope of electricity distribution. Some studies have addressed the challenges of 
regulators in estimating the efficiency measure (Irarstoza, 2003; Lins, Sollero, Caloba, \& Silva, 2007).

Relationships among the constructs have been systematized according to literature in the form of a structural model, which enables future researchers to have a reference frame of relevant studies and a research foundation in this area of knowledge. Several studies have addressed specific characteristics of performance in the electrical sector (Abbott, 2005; Delmas \& Tokat, 2005; Fillippini \& Wild, 2001; Giannakis, Jamasb, \& Pollitt, 2005; Growitsch, Jamasb, \& Pollitt, 2009; Nemoto \& Goto, 2004).

Finally, this study also offers a contribution to the Brazilian Electrical Energy Agency (Aneel, in Portuguese), a regulatory agency, providing mechanisms to guide tariff adjustments, seeking a balance between costs and the need for investments allied to tariff affordability.

\section{Literature review}

\subsection{Information on the background of the Brazilian electrical sector}

In Brazil, the electrical sector reform was based on a paradigm shift of the system's business model. Until mid-1990s, the paradigm involved the vertical integration of the various segments (generation, transmission, distribution and commercialization), all led by the government. Almost all countries operated the electrical sector through public sector entities, which enabled them to establish socially desirable policies (Laffont \& Tirole, 1991).

Aneel was created in 1996, an autarchy under a special regime, linked to the Ministry of Mines and Energy (MME), to provide favorable conditions for an electrical energy market with balanced conditions among agents and for the benefit of society (Agência Nacional de Energia Elétrica, 2015).

Another important change was introduced with Law No. 10,848, dated March 15 2004, preventing concessionaires, licensees and authorized public service concessionaires distributing electrical energy, acting within the National Integrated System (SIN), from verticalizing their activities in the chain of generation, transmission and sale of energy to consumers, as well as from participating in other companies, directly or indirectly.

In practice, such change implied the corporate deverticalization of several entities, forcing economic-financial information, previously aggregated by combined operations (generation, transmission, distribution and commercialization), to reflect each segment separately.

As for energy distribution, the reform introduced principles of a "pseudo" competitive market. The legislator considered that it was socially convenient for this activity to develop geographical monopolies due to a significant economy of scale in the distribution technology. The economy of scale enables the individual cost of the entity to decrease with the rise of population density in the area of operation.

Basically, the goal of benchmarking regulation is to produce an "artificial" competition between monopoly agents and a yardstick competition type of efficiency reference, proposed by Shleifer (1985). This corresponds to a competition by comparison, in which the rate of return of each distributor is neither assured nor limited, but depends on indicators based on the benchmark.

The main problem of this methodology is the complex application and the argument that the efficiency gains obtained are not always shared with final consumers. In addition, ArcosVargas, Núñez, and Ballesteros (2017) observed that a significant reduction in costs may also lead to a deterioration in service quality, based on a study carried out in nine European countries. 
RAUSP

55,2

180

\subsection{Theoretical model and research hypotheses}

Company efficiency stems from the quality of corporate governance and management control systems, so several theoretical and empirical studies document an association between these constructs. Examples are Simon (1960), Aguilera et al. (2008), Kenneth and Stede (2011) and Catelli (2013). The relationship between corporate governance and efficiency is not trivial, because only companies with effective governance systems would survive in the market, in a state of equilibrium (Gilson, 1996).

Guerreiro (1989)[1] discusses the interrelationship between intangible and tangible systems by saying that:

[...] in every company, people (social subsystem)[2], equipped with power and responsibility (formal subsystem)[3] and conditioned by certain restrictive principles (corporate governance)[4], make decisions (management subsystem) with the aid of information (information subsystem) that impact operations (physical-operational subsystem), to fulfill the purpose of the company (institutional subsystem)[5].

Largely supported by literature review, these concepts interact with one another and organize themselves into a system of constructs. These systems are not directly observable, but are manifested through variables or indicators. The constructs, therefore, are systems emerging from the existing literature and empirical validation, and are related to efficiency.

Company theory is the conceptual foundation where studies on corporate governance are established. It is argued that governance is important to ensure efficiency in the allocation of economic investments. In this sense, Shleifer and Vishny (1997) conceptualize corporate governance as a set of mechanisms by which providers of corporate capital ensure that companies receive adequate returns on their investments.

Throughout the twentieth century, important studies have emerged as those of Alchian and Demsetz (1972), Williamson (1975) and Jensen and Meckling (1976). Since then, there is a wide variety of literature that suggests a relationship between governance indicators and efficiency indicators. Broadly, studies show that the governance system positively influences the management system and efficiency.

That said, the following hypothesis is formulated:

H1. The Governance System positively influences the entity's Management System.

The variables associated with the information system are mainly supported by the theory of economic regulation proposed by Stigler (1971). The assumptions of this theory are:

- the state has control over public services and, therefore, it can use these services to benefit a certain group of interest; and

- agents are rational and make choices that maximize their well-being.

This approach helped to develop ideas about the possibilities of economic regulation being applied as a solution to a series of economic problems. The most important of these ideas was the regulatory design improvement by Stigler (1971), resulting in the consolidation of the idea that regulation is the appropriate response to promote balance between the various distinct and often conflicting interests between agents and society.

Taking into account these discussions, the following hypothesis is formulated:

H2. The Information System positively influences the entity's Management System.

The conceptual basis of the variables associated with the structural system is based mainly on two theories: company theory and stakeholder theory. The most commonly used 
definition in the literature of the term stakeholder is that of Freeman (1984), which refers to any individual or group that may affect the attainment of organizational goals or is affected by the process of pursuing these goals. Freeman (1984) adds that stakeholders are groups that have a legitimate right over the organization, which includes shareholders, employees, unions, clients, suppliers, creditors, among others.

Several empirical studies have addressed the interactions between company structure and efficiency, such as Arocena and Price (2002), Kwoka (2002), Nemoto and Goto (2004), Delmas and Tokat (2005) and Arocena (2008). In general, the authors point out that the structure of the firm has a positive influence on the management system and efficiency of entities.

Based on the above, the following hypothesis is formulated:

H3. The Structural System positively influences the entity's Management System.

The management model that forms it should privilege values and beliefs that foster group identity building with a high degree of internal cohesion, clear responsibility for the activities through the correct identification of the results generated by the decisions made, and creation of management processes that can produce the best plans to ensure continuity and increase effectiveness levels.

In this sense, some research papers were carried out to identify the various variables that can affect the formation and maintenance of an individual's commitment, as well as certain characteristics of work and organization as antecedent variables (Meyer, Irving, \& Allen, 1998; Meyer \& Herscovitvh, 2001; Valadares \& Da Silva, 2007).

As Fleury (1991) states, the study of culture makes it possible to understand the adopted forms of management, labor relations and control mechanisms in the organization. It is also possible to notice the increased number of studies analyzing the efficiency of these systems in terms of influence on employee performance and corporate productivity.

From the above-mentioned information, the following hypothesis is formulated:

H4. The Management System positively influences the entity's Sociocultural System.

The variables associated with the sociocultural system are based on Hofstede's (1980) study, whereby discrepancies in people's behavior can be explained by cultural differences (cultural dimensions theory).

His theory provides a framework for examining how cultural values affect behavior and gives clues about how people act according to the local culture. The theory has six cultural dimensions: power distance, individualism versus collectivism, aversion to uncertainties, masculinity versus femininity, long-term orientation and compliance versus repression.

In this way, the organizational culture, composed of beliefs and values, affects the efficiency levels of the activities performed when determining the degree of importance of the variables inherent to the activities.

Based on the affirmation above, the following hypothesis is formulated:

H5. The Sociocultural System positively influences entity's Efficiency.

Based on the previous hypotheses, it is possible to establish a theoretical model with six constructs and five hypotheses. This model represents a theory about how systems (management, governance, information, structure and sociocultural) influence entity efficiency. It is understood that efficiency is transversal; that is, it permeates all areas of the organization, affecting the way the entity organizes itself and conducts its operations. Based on the literature review, Figure 1 presents the proposed theoretical model in the form of a path diagram. 


\section{RAUSP}

55,2

\section{2}

Figure 1.

Theoretical model

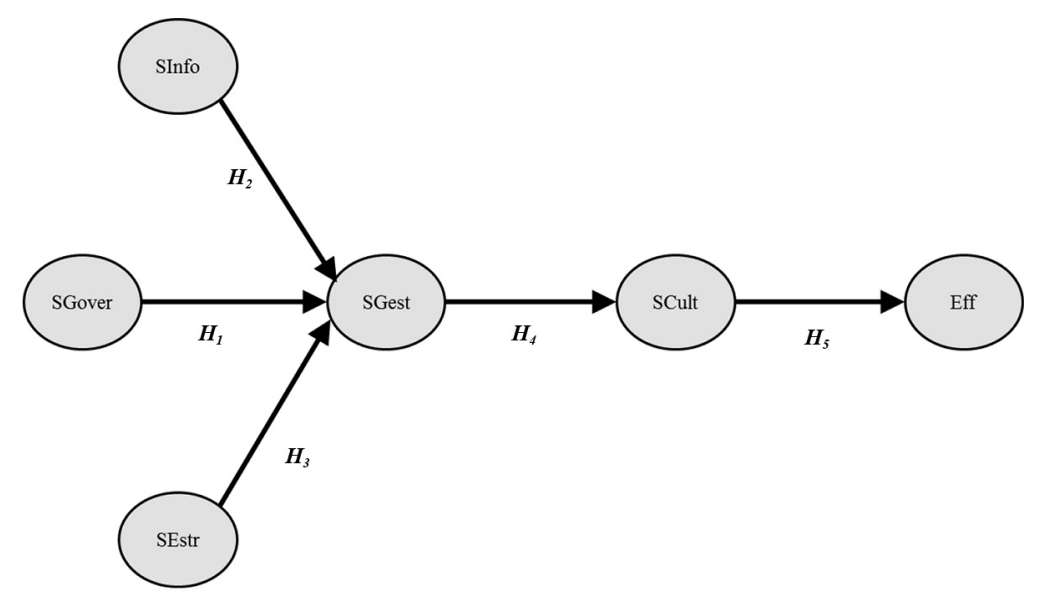

Source: Created by the author

This set of latent variables (constructs) and their interactions form a structural equation model (SEM). The ellipses represent latent variables (Efficiency - Eff, Governance System SGover, Information System - SInfo, Structural System - SEstr, Management System SGest and Sociocultural System - SCult) and arrows indicate the direction of the influence among these variables. It is only possible to measure these latent variables by observing manifest variables, the latter being directly measurable (Marôco, 2010).

The relationships between the six constructs, represented by unidirectional arrows, reveal the a priori understanding, supported by literature, of how these influences occur. The hypotheses, however, can only be confirmed by means of empirical data, following the procedures shown in Section 4.

\section{Research methodology}

\subsection{Universe and sample definition}

Information was extracted, in large part, from the database of the Brazilian Electrical Energy Agency (Aneel), i.e. the regulatory agency of the electrical sector. In Brazil, up to 2015, there were 63 electricity distribution companies. A total of 62 entities were selected, forming a balanced panel from 2010 to 2014 . The period was chosen due to the availability of data, but it was not possible to make updates because Aneel's website was reformulated in 2015. In addition, there have been corporate changes since 2017, making it impossible to obtain the same set of companies for analysis.

Companhia Energética de Roraima (CERR, in Portuguese) was excluded from the sample due to poor data disclosure. It was understood that this entity's information was not sufficient for an adequate analysis and could compromise the results of the model proposed in the study.

\subsection{Data collection and processing}

The entities reviewed periodically update their information with the regulatory agency, providing detailed information on operational and financial aspects. This includes, for example, manageable costs, number of customers served, extension of the network, energy demanded, among other aspects. 
In addition, Aneel required, under Normative Resolution No. 396, issued on February 23, 2010, information that adequately represents the economic and financial status of concessionaires and licensees of electrical energy transmission and distribution. Among the data disclosed, one can find the Regulatory Accounting Statements (DCRs, in Portuguese) of these concessionaires and licensees: Regulatory Balance Sheets (BPREG, in Portuguese), Regulatory Statement of Income (DREREG, in Portuguese), among others. Numbers are informed electronically by the agents themselves, but are subject to the supervision of the regulatory agency.

It should be noted that the phenomenon under study deals with influences of variables in a specific time period (2010-2014). This phenomenon, however, occurs continuously over time, whose effects may or may not have been captured by the selected time window. There were no missing values in the sample.

Table I shows the data treatment for the operationalization of variables.

At the limit, when it was not possible to recover any quantitative information, the arithmetic interpolation method was used, based on data collected from that entity. This occurred in less than 0.3 per cent of the data collected. Therefore, we worked with a balanced panel in statistical analysis with 310 complete observations.

Some variables were not included in the study to capture regulatory risk management directly due to data unavailability. On the other hand, the set of variables chosen captures the effect of indirect regulatory risk management.

\subsection{Benchmarking methods}

Benchmarking models can be defined as a process of comparing a performance measure against a benchmark (Farsi et al., 2006). Efficiency is usually measured as the distance to a cost frontier, formed by input allocation potential. Efficiency can be estimated using a variety of models, but classified into two main categories: parametric and non- parametric ones. Several studies have reported discrepancies in efficiency estimates among different approaches and model specifications (Estache, Rossi, \& Ruzzier, 2004; Farsi et al., 2006; Jamasb \& Pollitt, 2003).

DEA is a non-parametric method and uses linear programming to calculate the efficiency frontier or "best practices" of a sample (Charnes et al., 1978; Farrell, 1957). In this approach, cost frontier is considered as a deterministic function of the observed variables and it is easier to estimate using fewer observations.

The parametric approach, such as the SFA, assumes a parametric form for the cost frontier and a stochastic element in its function. In this method, the error term is divided into two parts: The first part $u$ i is a non-negative perturbation reflecting the effect of inefficiency, and the second component, $v \mathrm{i} \sim N\left(0, \sigma^{2}\right)$, is a symmetric perturbation that captures statistical noise.

For the purposes of this study, the variables that make up the calculation of the efficiency indicator are the same as those established by Aneel's model with three outputs and one input, according to Resolutions No. 457, issued on November 9, 2011, No. 640, December 16, 2014, and No. 660, April 28, 2015. In the definition of regulatory operating cost input, the accounting costs practiced by distribution companies are observed, according to DREREG. The data source for the outputs includes: number of consuming units, distributed energy volume and network density (Agência Nacional de Energia Elétrica, 2015).

\subsection{Structural equation modeling}

The SEM proposed in this study is a type of statistical model called "reflective model". In such models, latent variables are manifested in the variables observed; that is, they produce 
RAUSP
55,2

\begin{tabular}{lll}
\hline Groupings & Codes & Variables \\
\hline Variables used by & cst & Manageable costs \\
benchmarking & area & Concession area \\
models & ext & Network extension \\
& den & Network density \\
& uc & Number of consuming units \\
& ed & Distributed energy \\
Variables associated & ts & Type of system \\
with the Information & & Interruption equivalent \\
System & dec & duration \\
& fec & Interruption equivalent \\
& & frequency \\
& quali & Abradee Quality Award \\
& & Vertical Integration \\
Variables associated & int & Entity size \\
with the Structural & & Freedom of association \\
System & sind &
\end{tabular}

Operationalization

Variables associated with the Information System sind

Freedom of association

etica Requirement of ethical standards and social responsibility

Variables associated ocplp with Sociocultural System

ci

Short-term vs. long-term orientation

\begin{tabular}{|c|c|c|}
\hline \multirow[t]{2}{*}{ System } & $\mathrm{ci}$ & Uncertainty control \\
\hline & di & Hierarchical distance \\
\hline \multirow{3}{*}{$\begin{array}{l}\text { Variables associated } \\
\text { with the Governance } \\
\text { System }\end{array}$} & end & Indebtedness \\
\hline & gov & Government control \\
\hline & cap & Concentration of capital \\
\hline
\end{tabular}

Variables associated va with the Management System cresc dpl

Added value

Market growth

Evolution of shareholders' equity (PL)

Efficiency Scores crs

CRS-DEA model efficiency scores vrs VRS-DEA model efficiency scores

Table I.

Variable sfa SFA Method efficiency scores

DREREG, Plot B

Aneel's website

Aneel's website

Aneel's website

Aneel's website

Aneel's website

$0=$ Connected

$1=$ Isolated

Aneel's website

Aneel's website

Associação Brasileira de Distribuidores de Energia Elétrica (2015)

$0=$ not integrated

$1=$ integrated

Total Asset (BPREG)

$0=$ does not follow International Labor Organization standards (Restricted)

$1=$ follows and/or encourages International Labor Organization standards (flexible)

$0=$ does not require standards

$1=$ requires or at least suggests standards Invest. in qualification/Gross payroll

Turnover $=$ average $($ admission + dismissal)/dismissal

Higher and lower remuneration. Available in the Social Balance Sheet Current Liabilities + Non-Current Liabilities/Total Assets (BPREG) $0=$ there is no government control $1=$ there is government control $0=$ not concentrated $(<90 \%$ of the major shareholder interest)

$1=$ concentrated $(>90 \%$ of the major shareholder interest)

Added value to be distributed (Added Value Statement)

Energy distrib. $t$ /Energy distrib. $t-1$

PL $t$ minus PL $t-1$

DEA application

DEA application operationalization

Source: Created by the author 
effects on the manifested variables. Additionally, as observed by Marôco (2010), the set of manifested variables of the same construct presents a positive correlation among them.

Figure 2, following SEM standards, presents a SEM describing the influences of certain factors on the efficiency of electricity companies. The model consists of two parts: structural model (gray area) and measurement model (set of indicators outside the gray area). The structural model includes six constructs (ellipses) and their interactions (unidirectional arrows). The measurement model consists of particular sets of manifest variables (rectangles).

It is possible to observe in the previous figure a model of six latent variables: latent variable Efficiency $\left(\eta_{1}\right)$, operationalized by three manifest variables ( $\chi_{1}$ sfa, $\left.\chi_{2} \operatorname{vrs}, \chi_{3} \mathrm{crs}\right)$; latent variable Sociocultural System $\left(\eta_{2}\right)$, operationalized by three manifest variables $\left(\chi_{4} \mathrm{di}\right.$, $\chi_{5}$ ci, $\chi_{6}$ ocplp); latent variable Management $\operatorname{System}\left(\eta_{3}\right)$, operationalized by three manifest variables $\left(\chi_{7} \mathrm{dpl}, \chi_{8} \mathrm{cresc}, \chi_{9} \mathrm{va}\right)$; latent variable Information System $\left(\eta_{4}\right)$, operationalized by four manifest variables ( $\chi_{10}$ ts, $\chi_{11}$ quali, $\chi_{12}$ fec, $\chi_{13}$ dec); latent variable Structural System $\left(\eta_{5}\right)$, operationalized by four manifest variables $\left(\chi_{14}\right.$ porte, $\chi_{15}$ etica, $\chi_{16}$ sind, $\chi_{17}$ int); and the latent variable Governance System $\left(\eta_{6}\right)$, operationalized by three manifest variables $\left(\chi_{18}\right.$ cap, $\chi_{19}$ gov, $\chi_{20}$ end).

Residuals of latent and manifest variables are designated by letter "e", which represents the part explained by other variables not considered in the model. Factorial weights are represented by lambda $(\lambda \chi)$ where $\mathrm{x}$ is the manifested variable number, from 1 to 20 . Structural coefficients are represented by gamma $(\gamma \eta)$, where $\mathrm{h}$ is the number of the hypothesis, from $\mathrm{H} 1$ to $\mathrm{H} 5$.

\section{Results and discussions}

\subsection{Data description}

Table II below shows the descriptive statistics of the variables used in this study.

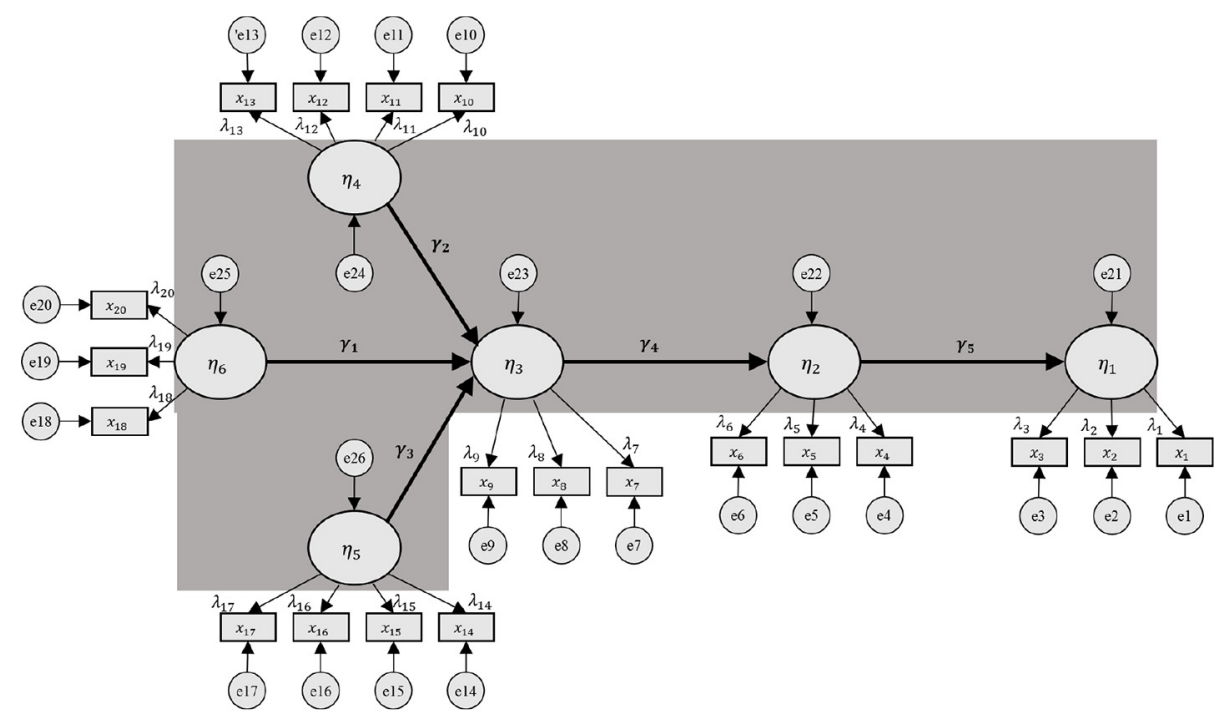

Source: Created by the author

Figure 2 . SEM 


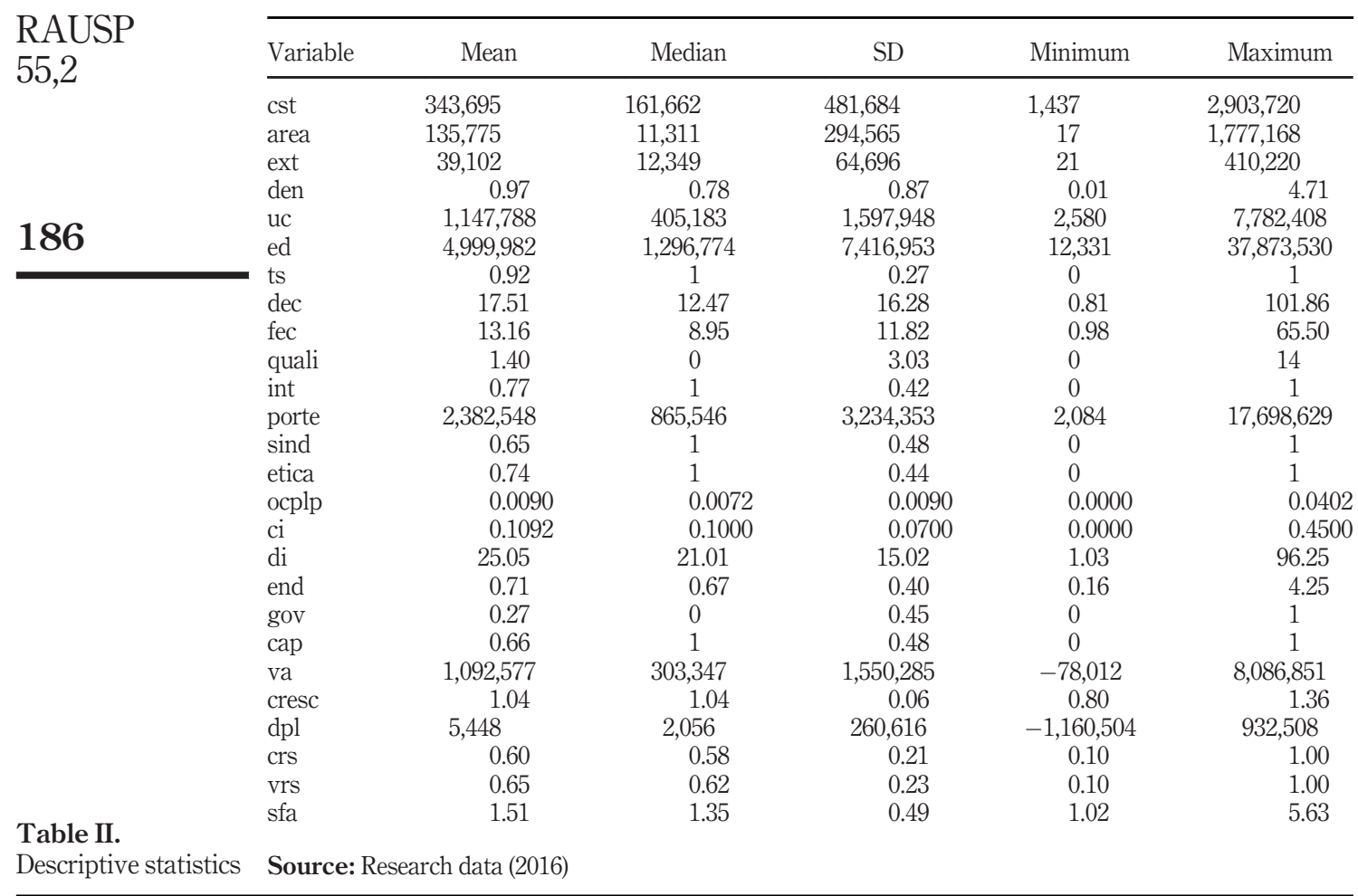

Regarding data in Table II, great variability is noted among the entities analyzed, as indicated by the minimum and maximum values of the variable "Manageable costs" ("cst"). A concentration around the intervals $0.5-0.7$ is noted in DEA scores, with tendency of growth in the period.

Linear transformation was only made for the indebtedness variable ("end"), improving adjustment results of the model. However, the linear transformation of this variable did not affect the calculation of factorial loads calculated by SEM.

Using the chi-square $\left(\Delta \chi^{2}\right)$ difference test, according to Steiger, Shapiro, and Browne (1985) and Brown (2006), models with and without transformed data are invariant, since the difference is not statistically significant among the models.

4.2 Validation of the proposed model

Assumption evaluation then represents a first step in SEM to avoid biased results. Thus, we analyzed:

- independence of observations;

- treatment of missing values;

- univariate and multivariate normality;

- absence of multicollinearity;

- outliers; and 
- the presence of non-zero sample covariates. Test results do not suggest significant problems in the observations.

After evaluating the quality of measurement sub model adjustments, plausibility of the complete model was sought, using the same indexes applied to the measurement model with the incorporation of parsimony indices. The objective is to verify if the correlational structure of measurement sub models adequately reproduces the empirical evidence of the sample. Hair et al. (2005) suggest three groups of adjustment indices: Absolute indices; distribution companies Relative indices and Parsimony indices. The evaluation of parsimony indices enables us to verify if the model has a better fit by adding parameters or relations, insofar as it remains as simple as possible (parsimonious).

Global model estimation was performed with the software IBM ${ }^{\circledR}$ SPSS ${ }^{\circledR}$ Amos 18.0. We verified that the initial model did not adequately reproduce the correlation structure of empirical data. One of the alternatives is to re-specify the model using the suggestions of modification indexes provided by the software.

In the re-specification process, repeated rounds of model adjustment were made. These steps have led to improvements in different measures until they reached the required levels of acceptance.

Table III shows the statistical values of the initial model and the last re-specified model.

The model included 50 variables (25 observed and 25 non-observed). Thirty-one loads and 18 estimated factorial weights, 4 covariances and 25 variances (47 parameters in total) were fixed. Thus, the number of different elements of the covariance matrix was 190 with 143 degrees of freedom $(g l=190-47=143)$. The maximum likelihood method was used and the algorithm reached the minimum of the discrepancy function in the iterative process for $\chi^{2}=376.233$. Analyzing Table III above, the indices used comply with the references suggested by literature (Kline, 2011; Marôco, 2010).

As a way of obtaining a better fit for the model, four relationships among the errors of the variables were allowed, as suggested by IBM ${ }^{\circledR}$ SPSS ${ }^{\circledR}$ Amos, version 18.0: 1 . size of the

\begin{tabular}{lccc}
\hline Indexes & Initial model Re-specified model Levels of acceptance \\
\hline $\begin{array}{l}\text { Adjustment tests } \\
\text { Chi-square }\left(\chi^{2}\right)\end{array}$ & 616.077 & 376.233 & The lower the better \\
Degrees of freedom $(g l)$ & 147 & 143 & $>1$ \\
p-value & 0.000 & 0.000 & $<0.05$ \\
Absolute indices & & & \\
Standardized chi-square $\left(\chi^{2} / g l\right)$ & 4.191 & 2.631 & $<3$ \\
Root Mean Square Error of Approximation (RMSEA) & 0.113 & 0.085 & $<0.08$ \\
Goodness of Fit Index (GFI) & 0.819 & 0.912 & $>0.90$ \\
Relative indices & & & \\
Comparative Fit Index (CFI) & 0.703 & 0.949 & $>0.90$ \\
Normed Fit Index (NFI) & 0.679 & 0.921 & $>0.90$ \\
Tucker-Lewis Index (TLI) & 0.635 & 0.908 & $>0.90$ \\
& & & \\
Parsimony indices & & & \\
Parsimony GFI (PGFI) & 0.552 & 0.766 & $>0.60$ \\
Parsimony CFI (PCFI) & 0.515 & 0.776 & $>0.60$ \\
Parsimony NFI (PNFI) & 0.579 & 0.753 & $>0.60$
\end{tabular}

Source: Research data (2016)

Table III.

Quality indices of adjustment of the initial and respecified global model 
RAUSP

55,2

\section{8}

entity (porte) $\leftrightarrow$ added value (va); 2 . freedom of association (sind) $\leftrightarrow$ government control (gov); 3. vertical integration (int) $\leftrightarrow$ capital concentration (cap); 4. indebtedness (end) $\leftrightarrow$ Information System (SInfo). 18.0.

Figure 3 shows the re-specified output model generated by IBM ${ }^{\circledR}$ SPSS ${ }^{\circledR}$ Amos, version

For purposes of identification, no constraints were imposed on structural parameters, enabling latent variables to correlate freely during the model estimation.

\subsection{Result discussion}

In IBM ${ }^{\circledR}$ SPSS ${ }^{\circledR}$ Amos 18.0, and in other SEM softwares, reports are generated with the Critical Ratio (CR); that is, the result of dividing the estimated value (Estimate) by its standard error (Standard Error - SE). IBM ${ }^{\circledR}$ SPSS Amos 18.0 handles critical ratios (CR) as " $z$ values", assuming large sample sizes (more than 100 ). Typically, CR values $>1.96$ and $p$ value $<0.05$ (two-tailed test) are acceptable. Table IV summarizes the results provided by the software.

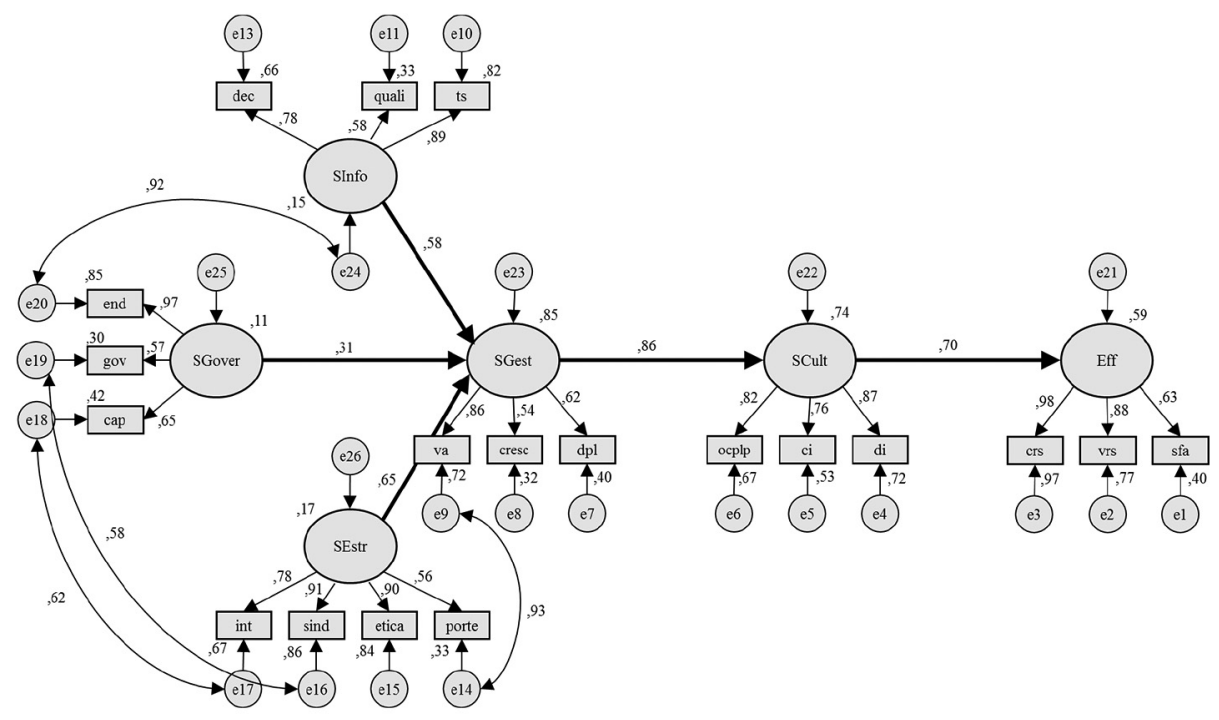

Source: Research data (2016)

Figure 3.

SEM results

\begin{tabular}{lcccccl}
\hline Relationship & Estimate & SE & CR & $p$ & Label & Result \\
\hline SGest $\leftarrow$ SGover & 0.950 & 0.529 & 1.794 & 0.073 & par_1 & Rejection \\
SGest $\leftarrow$ SInfo & 0.582 & 0.205 & 2.831 & 0.005 & par_2 & Non-rejection \\
SGest $\leftarrow$ SEstr & 0.514 & 0.149 & 3.445 & $* * *$ & par_3 & Non-rejection \\
SCult $\leftarrow$ SGest & 0.637 & 0.312 & 2.041 & 0.041 & par_4 & Non-rejection \\
Eff $\leftarrow$ SCult & 1.006 & 0.419 & 2.403 & 0.016 & par_5 & Non-rejection
\end{tabular}

Source: Research data (2016) 
The direct effect of the Information System on the Management System is significant (CR = 2.831 and $p<0.05$ ). By analyzing standardized factorial loads, variable ts (type of system) was the highest expression with 0.89 , followed by dec (interruption equivalent duration) with 0.78 , while the lowest expression was variable quali (Abradee Award) with 0.58.

The direct effect of the Structural System on the Management System is significant $(\mathrm{CR}=3.445$ and $p<0.001$ ). These modeling results show that variables sind (freedom of association) and etica have the highest factorial load, with 0.91 and 0.90 , respectively. One possible explanation is that managers' beliefs and values have a strong influence on how the entity structures itself, which reflects on the execution (management) of the activities. The variables vertical integration (factorial load $=0.78$ ) and size (factorial load $=0.56$ ) are less expressive.

The Management System has significant effects on the Sociocultural System (CR $=2.041$ and $p<0.05)$. These results are consistent with several empirical studies on the subject. Pettigrew (1996) understands that one of the most relevant variables in business - the organizational culture - is a true channel for good performance. Variable va (value added) was the most expressive in the construct, with a factorial load $=0.86$. Variables dpl (evolution of stockholders' equity) and growth (market growth) are less expressive, with factorial loads equal to 0.62 and 0.54 , respectively.

The Sociocultural System $\rightarrow$ Efficiency trajectory is statistically significant (CR $=2.403$ and $p<0.05$ ). The adjusted model shows the factorial load of the variable di (hierarchical distance) as the most expressive one, equal to 0.87 , followed by variable ocplp (short-term $\times$ long-term) and ci (uncertainty control): 0.82 and 0.76 , respectively.

Contrary to what was expected, $H 1$ (the Governance System positively influences the entity's Management System) was not confirmed at the 5 per cent level ( $t$-test). This result is in conflict with the result of several other studies (Bozec \& Dia, 2007; Destefanis \& Sena, 2007; Leal, 2004; Lehmann et al., 2004; Macedo \& Corrar, 2012; Peixoto, Ferreira, \& Lopes, 2011; Zelenyuk \& Zheka, 2006). Broadly, these studies show that governance exerts a positive influence on the management and efficiency of entities.

The rejection of $H 1$ may be tied to data availability itself for study purposes. The time window chosen and depuration of other effects not studied in this work may also have interfered with the result. Regarding the theoretical support on the subject, no study evaluating the proposed constructs was found.

Regulatory costs, estimated by Aneel and applied in tariff revision processes, may be higher or lower than the actual costs incurred by the distributor. As discussed earlier, it is incentive regulation; that is, tariff reviews are applied on regulatory costs considered reasonable, given a certain level of efficiency.

Considering that the entities analyzed herein operate under different conditions (information, structure, management, culture, etc.), as suggested by the results of this study, the "management" effect affects entity performance in a constant way. Even so, such heterogeneity among entities is not properly considered by the regulatory model and results may provide discrepant estimates of regulatory costs.

In practice, this discrepancy has a direct impact on the formulation of tariff policies, implying an excessive burden on economic agents and/or consumers. It is therefore recommended that the regulatory agency reviews its regulatory model and takes the findings of this study into consideration.

\section{Conclusions and recommendations for future studies}

After assessing articles on efficiency, most of the studies available are focused on the analysis of efficiency measures, without providing a deep discussion on the factors that lead 
RAUSP

55,2

to efficiency variation. Focusing on efficiency estimation restricts the study to a particular sample or geographical area (Agrell et al., 2013; Cullmann, 2012). Gaps found in literature encouraged this research because we considered important to study the influences on the efficiency of electricity distribution companies from a multivariate perspective.

In this context, this study aims to evaluate the efficiency of Brazilian electricity distribution companies based on the construction of a structural model that enables the identification of a structure of relationships between the representative variables and efficiency.

The statistical results confirmed the expected influences of the manifested variables on efficiency. All hypotheses were confirmed, except for $H 1$ (the Governance System positively influences the Management System of the entity).

The fact that an adequate information system is associated with efficiency gains is emphasized, but it is necessary for the manager to carefully evaluate the needs of the entity and the effects of resource allocation. In the case of electricity distribution companies, the empirical analysis revealed a positive influence of the information system on management.

Future studies can identify the meaning of grouped manifest variables, enabling the designation of two or more constructs based on the latent variables proposed in the model. A longitudinal study is also suggested to answer questions regarding the evolution of the interaction among these variables in a larger time frame or to verify the consistency of the model in different groups.

Another suggestion is to verify the model in locus. Future research may validate the proposed general model in each entity (case study), enabling fine-tune settings for the conclusions.

\section{Notes}

1. The quotation below can be found in Guerreiro's doctoral thesis (1989), who originally formulated it. We chose to make reference to the thesis because the sentence quoted herein mentioned by other authors in different articles.

2. In this research paper, the social subsystem is called sociocultural system.

3. In this research paper, the formal subsystem is called structural system.

4. Guerreiro (1989) refers to the Corporate Governance subsystem as Management Model.

5. The institutional subsystem, according to Guerreiro (1989), is composed of the company's beliefs, values and mission. In this research paper, we assume that these elements are incorporated in Corporate Governance.

\section{References}

Abbott, M. (2005). Determining levels of productivity and efficiency in the electricity industry. The Electricity Journal, 18, 62-72.

Agência Nacional de Energia Elétrica. (2015). Aneel's Website. Institutional - A Aneel. Retrieved from www.aneel.gov.br

Agrell, P. J., Farsi, M., Filippini, M., \& Koller, M. (2013). Unobserved heterogeneous effects in the cost efficiency analysis of electricity distribution systems. CORE Discussion Papers, Université Catholique de Louvain, Center for Operations Research and Econometrics (CORE).

Aguilera, R. V., Filatotchev, I., Gospel, H., \& Jackson, G. (2008). An organizational approach to comparative corporate governance: Costs, contingencies, and complementarities. Organization Science, 19, 475-492.

Alchian, A., \& Demsetz, H. (1972). Production, information costs and economic organization. American Economic Review, 62, 777-795. 
Arcos-Vargas, A., Núñez, F., \& Ballesteros, J. A. (2017). Quality, remuneration and regulatory framework: Some evidence on the European electricity distribution. Journal of Regulatory Economics, 51, 98-118.

Arocena, P. (2008). Cost and quality gains from diversification and vertical integration in the electricity industry: A DEA approach. Energy Economics, 30, 39-58.

Arocena, P., \& Price, C. W. (2002). Generating efficiency: Economic and environmental regulation of public and private electricity generators in Spain. International Journal of Industrial Organization, 20, 41-69.

Associação Brasileira de Distribuidores de Energia Elétrica. (2015). Abradee's Website. Institutional Abradee Award. Retrieved from www.abradee.com.br

Bozec, R., \& Dia, M. (2007). Board structure and firm technical efficiency: Evidence from Canadian state-owned enterprises. European Journal of Operational Research, 177, 1734-1750.

Brown, T. A. (2006). Confirmatory factor analysis for applied research. New York, NY: The Guilford Press.

Catelli, A. (2013). Controladoria: Uma abordagem da gestão econômica - GECON (2nd ed.). São Paulo, Brazil: Editora Atlas.

Charnes, A., Cooper, W. W., \& Rhodes, E. L. (1978). Measuring the efficiency of decision making units. European Journal of Operational Research, 2, 429-444.

Cullmann, A. (2012). Benchmarking and firm heterogeneity: A latent class analysis for German electricity distribution companies. Empirical Economics, 42, 147-169. doi.org/10.1007/s00181010-0413-4.

Delmas, M., \& Tokat, Y. (2005). Deregulation, governance structures, and efficiency: The U.S. electric utility sector. Strategic Management Journal, 26, 441-460.

Destefanis, S., \& Sena, P. (2007). Patterns of corporate governance and technical efficiency in Italian manufacturing. Managerial and Decision Economics, 28, 27-40.

Estache, A., Rossi, M. A., \& Ruzzier, C. A. (2004). The case for international coordination of electricity regulation: Evidence from the measurement of efficiency in South America. Journal of Regulatory Economics, 25, 271-295.

Farrell, M. J. (1957). The measurement of productive efficiency. Journal of the Royal Statistical Society, 120, 253-290.

Farsi, M., Fillippini, M., \& Greene, W. H. (2006). Application of panel data models in benchmarking analysis of the electricity distribution sector. Annals of Public and Cooperative Economics, 77, 271-290.

Fillippini, M., \& Wild, J. (2001). Regional differences in electricity distribution costs and their consequences for yardstick regulation of access prices. Energy Economics, 23, 477-488.

Fleury, M. T. L. (1991). Cultura organizacional e estratégias de mudanças: Recolocando estas questões no cenário brasileiro atual. Revista de Administração, 26, 3-11.

Freeman, R. E. (1984). Strategic management: A stakeholder approach. Boston, MA: Pitman.

Giannakis, D, Jamasb, T., \& Pollitt, M. G. (2005). Benchmarking and incentive regulation of quality of service: an application to the UK electricity distribution utilities. Energy Policy, 33, 2256-2271.

Gilson, R. J. (1996). Corporate governance and economic efficiency: When do institutions matter. Washington University Law Quarterly, 74, 327-345.

Greene, W. H. (2005). Reconsidering heterogeneity in panel data estimators of the stochastic frontier model. Journal of Econometrics, 126, 269-303.

Growitsch, C., Jamasb, T., \& Pollitt, M. (2009). Quality of service, efficiency and scale innetwork industries: An analysis of European electricity distribution. Applied Economics, 41, 2555-2570.

Guerreiro, R. (1989). Modelo conceitual de sistema de informação de gestão econômica: Uma contribuição a teoria da comunicação e a contabilidade. Tese (Doutorado). Faculdade de Economia. Administração e Contabilidade, Universidade de São Paulo, São Paulo, SP, Brasil. 
RAUSP

55,2
Hair, J. F., Black, W. C., Babin, B. J., \& Anderson, R. E. (2005). Multivariate data analysis, Upper Saddle River, NJ: Prentice Hall.

Hofstede, G. (1980). Culturés consequences: International differences in work-related values (Vol. 5). Newbury Park, CA: Sage Publications.

Irarstoza, V. (2003). Benchmarking for distribution utilities: A problematic approach to defining efficiency. The Electricity Journal, 16, 30-38.

Jamasb, T. J., \& Pollitt, M. G. (2003). International benchmarking and regulation: An application to European electricity distribution utilities. Energy Policy, 31, 1609-1622.

Jensen, M. C., \& Meckling, W. H. (1976). Theory of the firm: Managerial behavior, agency costs and ownership structure. Journal of Financial Economics, 3, 305-360.

Kenneth, A. M., \& Stede, W. A. D. (2011). Management control systems: Performance measurement, evaluation and incentives (3rd ed.). Harlow, United Kingdom: Pearson.

Kline, R. B. (2011). Principles and practice of structural equation modeling. New York, NY: The Guilford Press.

Kwoka, J. (2002). Vertical economies in electric power: Evidence on integration and its alternatives. International Journal of Industrial Organization, 20, 653-671.

Laffont, J. J., \& Tirole, J. (1986). Using cost observation to regulate firms. Journal of Political Economy, $94,614-641$.

Laffont, J. J., \& Tirole, J. (1991). Privatization and incentives. Journal of Law, Economics, \& Organization, 7, 84-105.

Leal, R. P. C. (2004). Governance practices and corporate value: a recent literature review. Revista de Administração, 39, 327-337.

Lehmann, E., Warning, S., \& Weigand, J. (2004). Governance structures, multidimensional efficiency and firm profitability. Journal of Management and Governance, 8, 279-304.

Law n. 10,848, dated March 15 2004. (2004). Dispõe sobre a comercialização de energia elétrica, altera as leis nos 5.655, de 20 de Maio de 1971, 8.631, de 4 de março de 1993, 9.074, de 7 de julho de 1995, 9.427, de 26 de dezembro de 1996, 9.478, de 6 de agosto de 1997, 9.648, de 27 de Maio de 1998, 9.991, de 24 de julho de 2000, 10.438, de 26 de abril de 2002, e dá outras providências. Retrieved from http://www.planalto.gov.br/ccivil_03/_Ato2004-2006/2004/Lei/L10.848.htm

Lins, M. P. E., Sollero, M. K. V., Caloba, G. M., \& Silva, A. C. M. (2007). Integrating the regulatory and utility firm perspectives, when measuring the efficiency of electricity distribution. European Journal of Operational Research, 181, 1413-1424.

Macedo, M. A. S., \& Corrar, L. J. (2012). Comparative analysis of accounting and financial performance of companies with good corporate governance practices in Brazil. Revista de Contabilidade $e$ Controladoria, 4(1), 42-61.

Marôco, J. (2010). Análise de equações estruturais: Fundamentos teóricos, software \& aplicações. Pêro Pinheiro, Portugal: ReportNumber: Lda.

Meyer, J. P., \& Herscovitvh, L. (2001). Commitment in the workplace: Toward a general model. Human Resource Management Review, 11, 299-326.

Meyer, J. P., Irving, G., \& Allen, N. J. (1998). Examination of the combined effects of work values and early work experiences on organizational commitment. Journal of Organizational Behavior, 19, 29-52.

Nemoto, J., \& Goto, M. (2004). Technological externalities and economies of vertical integration in the electric utility industry. International Journal of Industrial Organization, 22, 67-81.

Peixoto, F. M., Ferreira, R. N., \& Lopes, A. L. M. (2011). Corporate governance and performance in the electricity sector using data envelopment analysis: A study in the Brazilian capital market. Conference on Performance Measurement and Management Control, The European Institute for Advanced Studies in Management, Nice, France. 
Pettigrew, A. M. (1996). A cultura das organizações é administrável?. In M. T. L. Fleury, \& R. M. Fischer, (Eds.). Cultura e poder nas organizações (pp. 145-153). São Paulo, Brazil: Atlas.

Shleifer, A. (1985). A theory of yardstick competition. The Rand Journal of Economics, 16, 319-327.

Shleifer, A., \& Vishny, R. (1997). A survey of corporate governance. The Journal of Finance, 52, 737-783.

Simon, H. A. (1960). The new science of management decision. New York, NY: Harper \& Row.

Steiger, J. H., Shapiro, A., \& Browne, M. W. (1985). On the multivariate asymptotic distribution of sequential chi-square statistics. Psychometrika, 50, 253-264.

Stigler, G. J. (1971). The theory of economic regulation. Chicago, IL: University of Chicago Press.

Valadares, R. D., \& Da Silva, J. R. G. (2007). The influence of performance management systems on the commitment of individuals in the current context of organizations. Revista Gestão e Planejamento, 8, 51-67.

Williamson, O. (1975). Markets and hierarchies: analysis and antitrust implications (1st ed.). New York, NY: The Free Press.

Zelenyuk, V., \& Zheka, P. (2006). Corporate governance and firm's efficiency: The case of a transitional country, Ukraine. Journal of Productivity Analysis, 25, 143-157.

\section{Corresponding author}

Diego Rodrigues Boente can be contacted at: diegoboente@gmail.com

Associate Editor: Luiz Paulo Fávero

For instructions on how to order reprints of this article, please visit our website: 